\title{
DSM-5 and the rough ride from approval to publication
}

\author{
Edward Davies US news and features editor, BMJ
}

Since the American Psychiatric Association (APA) approved the fifth edition of its Diagnostic and Statistical Manual of Mental Disorders in December last year, barely a day has passed without criticism and comment in the professional, national, and international media. DSM-5 is intended to supersede the existing psychiatric Bible, DSM-IV, which was published 13 years ago.

With the May publication date fast approaching, the New York Times recently printed some scathing opinion on diagnosis of depression (http://newoldage.blogs.nytimes.com/2013/01/24/ grief-over-new-depression-diagnosis), the Washington Post published an op-ed saying the manual does more harm than good (www.washingtonpost.com/opinions/psychiatrys-biblethe-dsm-is-doing-more-harm-than-good/2012/04/27/ gIQAqy0WIT_story.html), and the Huffington Post published a blog last month entitled "DSM-5: Science or dogma? Even some establishment psychiatrists embarrassed by newest diagnostic Bible" (www.huffingtonpost.com/bruce-e-levine/ dsm-5_b_2657667.html).

This week we too publish an opinion piece on DSM-5, centered on the controversial diagnosis of somatic symptom disorder (doi:10.1136/bmj.f1580)—and as I write, within 24 hours of online publication, we have already received several polarized responses.

The author of the view, Allen Frances, chair of the DSM-IV task force, voices staunch criticism of "the catch-all criteria" for diagnosis, and in forthright terms he claims that "millions of people could be mislabeled, with the burden falling disproportionately on women, because they are more likely to be casually dismissed as 'catastrophizers' when presenting with physical symptoms."

Rarely can any medical publication of any sort have so swiftly divided physicians and commentators. There is already enough analysis on this manual to fill several journals several times over, so I don't intend to add a great deal. But given the incredible heat DSM-5 is already generating, the process of its creation and dissemination at the very least seems to demand serious attention, while the proposal to have the manual evolve as new evidence appears is a clear improvement on a once-a-decade bombshell.

Cite this as: BMJ 2013;346:f1918

๑ B BMJ Publishing Group Ltd 2013 